

\title{
Aspectos paisajísticos de un sacrario español: la Pirámide de los Italianos (1938-1939) en el puerto del Escudo (Valdebezana, Burgos)
}

Landscape aspects of a Spanish sacrario: the Pyramid of the Italians (1938-1939) in the port of the Escudo (Valdebezana, Burgos)

\author{
José Miguel Muñoz Jiménez \\ Vocal de la Junta Nacional de la A.E.A.C., Espańa \\ josemiguelmunoz@telefonica.net \\ https://orcid.org/0000-0001-8215-5361
}

\section{Resumen}

Quiero proponer en este artículo una reflexión sobre cómo por la traslación a un bello paraje de nuestros montes cantábricos, de un sacrario de origen itálico -según G. P. Piretto, podría definirse sacrario como un mausoleo devenido en santuario-, el lugar se acaba convirtiendo en un ámbito de tipo ceremonial. Se trata de ponderar paisajísticamente los restos arqueológicos del cementerio que las tropas mussolinianas levantaron entre 1938 y 1939, para inhumar los restos de más de 300 soldados caídos en la sangrienta batalla del Escudo. En este ensayo se observa que, paisajísticamente, confluyen en la ubicación del santuario variados aspectos naturales y artificiales, históricos y

\begin{abstract}
I want to propose in this article a reflection on how by the translation to a beautiful place of our Cantabrian mountains, of a sacrario of italic origin-according to G.P. Piretto, it could be defined sacrario as a mausoleum turned into a sanctuary-, the place ends up becoming a scope of ceremonial type. It is scenically weigh the archaeological remains of the cemetery that mussolinianas troops erected between 1938 and 1939, to bury the remains of more than 300 soldiers killed in the bloody Battle of the Escudo. In this essay it is observed that, in landscape, various natural and artificial, historical and religious aspects converge in the location of the sanctuary, as well as, for the cultivated soul, a feeling of melancholy
\end{abstract}


religiosos, así como también, para el alma cultivada, se produce una sensación de frustración melancólica al contemplar el vandalismo que el monumento sufre en la actualidad.

Palabras clave: Paisaje histórico; paisaje ceremonial; santuario de montaña; Pirámide de los Italianos; arquitectura fascista. frustration occurs when contemplating the vandalism that the monument suffers in the news.

Keywords: Historical landscape; ceremonial landscape; mountain sanctuary; Pyramid of the Italians; fascist architecture.

Introducción: paisaje, santuario y arquitectura Fernando García-Mercadal, el gran arquitecto que tanto aportó a la renovación de la arquitectura española en el segundo tercio del siglo pasado, gustaba decir que los edificios formaban parte del paisaje natural de un país, como los árboles o las montañas. Su búsqueda de las verdaderas esencias de un patrimonio constructivo enraizado en lo mediterráneo, le llevó a defender su vinculación con un clasicismo cultural de raíces vernáculas, al tiempo que encontró en ello la base para la puesta al día de la arquitectura española respecto a las vanguardias occidentales ${ }^{1}$.

Con parecidas inquietudes, quiero proponer en este artículo una reflexión sobre cómo por la traslación a un bello paraje de nuestros montes cantábricos, de un sacrario de origen itálico -según G. P. Piretto, podría definirse sacrario como un mausoleo devenido en santuario-, el lugar se acaba convirtiendo en un ámbito de tipo ceremonial. Se trata de ponderar paisajísticamente los restos arqueológicos del cementerio que las tropas mussolinianas levantaron entre 1938 y 1939, para inhumar los restos de más de 300 soldados caídos en la sangrienta batalla del Escudo, decisiva acción de julio de 1937 que condujo semanas después a la conquista de Santander.

Así pretendo completar el estudio que se inició con la publicación de un artículo titulado "La Pirámide de los Italianos en el puerto del Escudo (1938-1939): documentación de su proceso constructivo" ${ }^{2}$, donde di a conocer importantes datos acerca de los responsables de su erección y la historia de las obras, y que siguió en otra revista con una segunda parte llamada "Una arquitectura de la memoria: tipo, estilo y simbología de la Pirámide de los Italianos en el puerto del Escudo (1938-1939)”" en la que pretendí valorar los aspectos artísticos y los méritos estéticos de tan exótica construcción.

En ambos casos concluía en la necesidad de una pronta intervención restauradora que llevara a salvar para el patrimonio histórico español un conjunto único, en razón de su origen extranjero y de otras muchas cualidades.

1. Al respecto vid. el acertado análisis de RODRíGUEZ GARCÍA, Ana, "Popular, regional y mediterráneo. Fernando García Mercadal y su tiempo", CASTAÑO PEREA, Enrique (ed.), Academia. Boletín RABASF, Anexo III. Fernando García Mercadal, 2017, págs. 185-220. Las palabras exactas del aragonés, publicadas en 1926, fueron: "la casa aquí es tan del paisaje como los árboles o los montes, la casa es como una vegetación natural".

2. MUÑOZ JIMÉNEZ, José Miguel, "La pirámide de los Italianos en el Puerto del Escudo (1938-1939): documentación de su proceso constructivo", Revista de Arqueología Sautuola, XXI, 2016, págs. 239-252.

3. MUÑOZ JIMÉNEZ, José Miguel, “Una arquitectura de la memoria: tipo, estilo y simbología de la Pirámide de los Italianos en el puerto del Escudo (1938-1939)", Butlletí de la Reial Academia Catalana de Belles Arts de Sant Jordi, XXXI, 2017, págs. 127-142. 


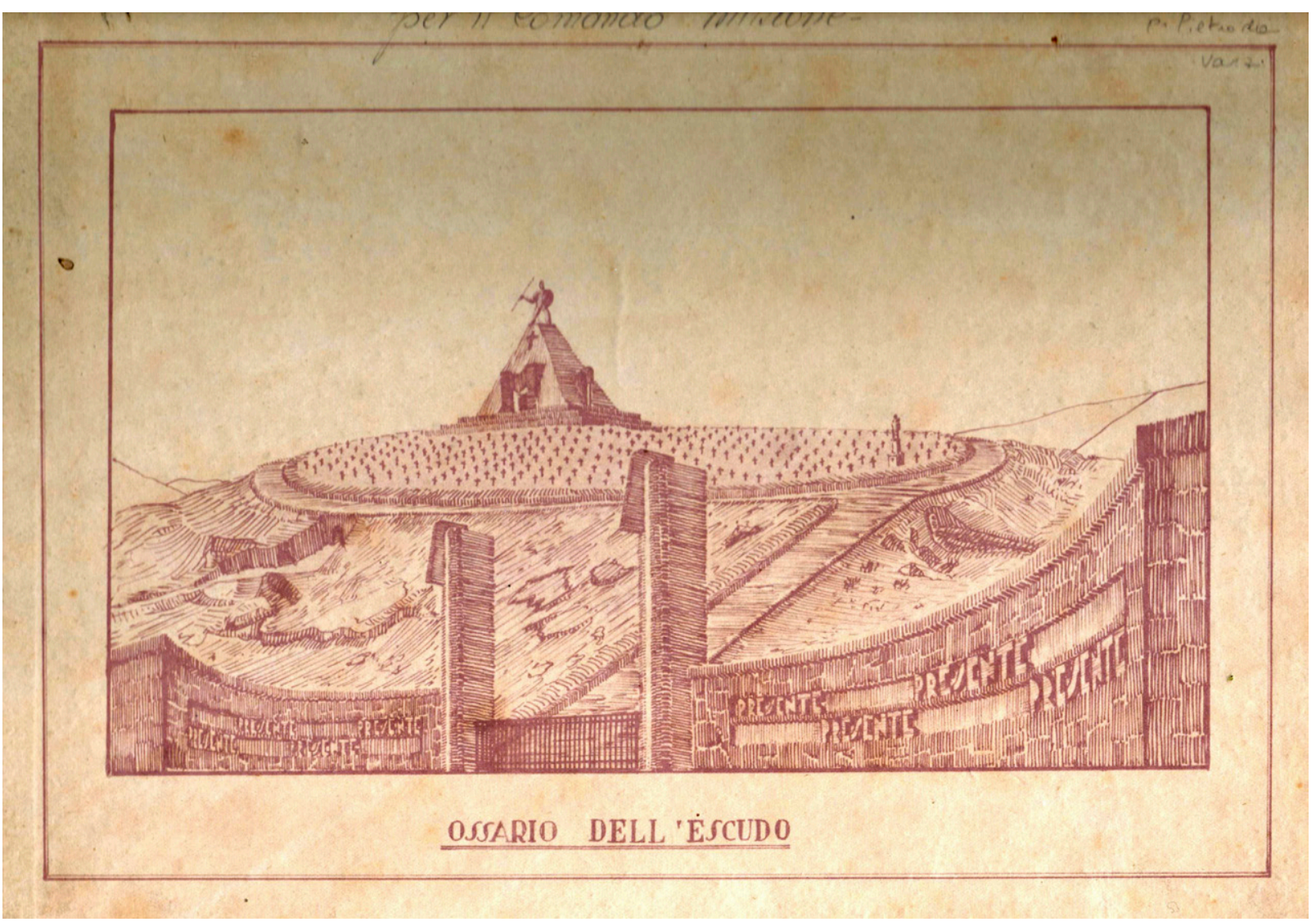

Fig. 2. Dibujo general del cementerio, quizás de mano del P. Bergamini. Foto Archivo Histórico Capuchinos de Génova.

Parece difícil, en el actual momento de nuestra nación, que los prejuicios políticos sean superados a favor de una memoria histórica verdadera y objetiva, acorde con el largo paso del tiempo transcurrido desde el conflicto que dio lugar a la obra que estudiamos. Mas superada semejante frustración, entiendo que aún faltaba por hacer esta tercera aportación que, a modo de paráfrasis, ayudara a ver los "Aspectos paisajísticos de un sacrario español: la Pirámide de los Italianos en el puerto del Escudo”.

No hay duda de que uno de los rasgos más admirables que se derivan de la Pirámide de los Italianos es, precisamente, su pertenencia a la serie de obras enmarcables en el fantástico Cementerio Ideal que, tan bellamente, pintó en magníficas acuarelas del año 1910 el arquitecto Teodoro Anasagasti (1880-1930). Se trata de una pintura para soñar, una arquitectura que, como en tantos de nuestros santuarios hispánicos de montaña, nació en aquel lugar y sólo para aquel lugar. Pues la visión romántica allí presente aúna lo religioso, lo histórico y lo paisajístico.

\section{La pirámide de los italianos documentada en su proceso constructivo}

El mausoleo del Escudo es una obra de aire italiano que se enmarca en la vanguardia característica de los años de entreguerras, la que fluctuó entre el futurismo, el fascismo y el más apreciable racionalismo arquitectónico. 


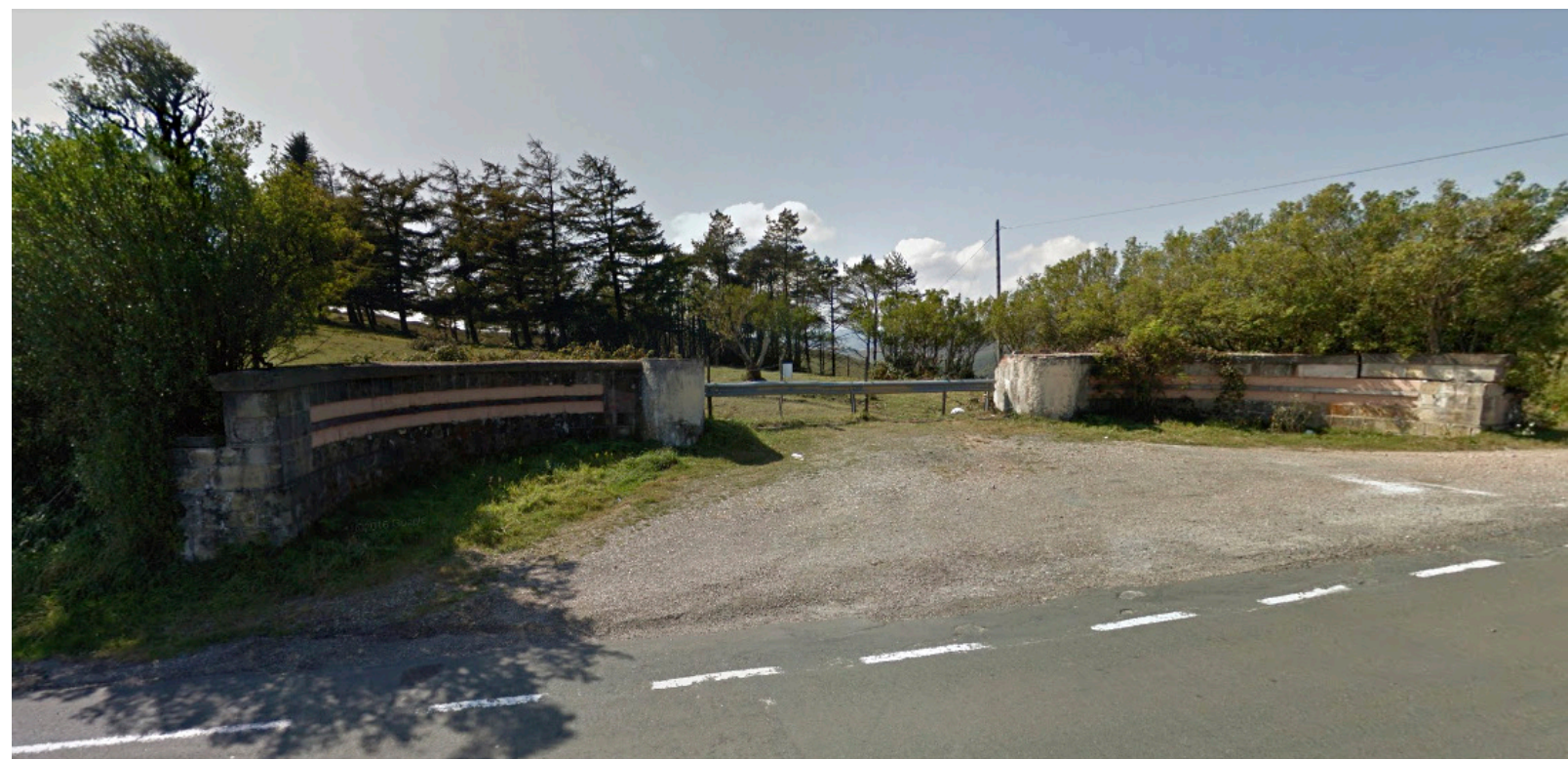

Fig. 3. Estado actual de la entrada monumental. Foto autor. 13-07-2017.

Podría aplicarse a este moritorio la categoría de montaña sagrada, en cuanto en origen tuvo algo, entre pagano y cristiano, de lugar de culto, de santuario alpestre, claramente deudor de concepciones utópicas y simbolistas.

Ello en un paisaje que se acomoda como anillo al dedo al modelo de otros majestuosos cementerios militares del norte de Italia -Grappa, Pasubio, Cimone,...- erigidos por el régimen fascista en honor de los soldados que lucharon en la Gran Guerra contra los imperios centrales. Todos, como este osario del Escudo, verdaderas "montañas de los caídos".

Se trata en efecto de la Pirámide de los Italianos, que hoy es ruina de la ruina en una carretera nacional condenada a la soledad y el abandono. Su autor, al parecer, fue un inédito arquitecto, escultor y grabador de origen dálmata y afincado en Milán, llamado Attilio Radic (1898-1967), del que he podido espigar muy pocos datos biográficos ${ }^{4}$. Al tiempo, el realizador material de la pirámide fue un bizarro capellán militar, el fraile Pietro Bergamini di Varza (1895-1962), también dotado de destreza artística, que un poco orgullosamente se atribuyó después todo el mérito del conjunto funerario 5 . Con todo, se podría concluir que el mausoleo de El Escudo fue una obra conjunta del arquitecto milanés y del excelente pintor capuchino, natural de Pavía.

4. MUÑOZ JIMÉNEZ, José Miguel, "La pirámide de los Italianos...", op. cit., págs. 241-243. Sabemos que Attilio Radic nace en Milán el 16 de mayo de 1898, y que se diplomó en arquitectura en la Academia de Brera. Un par de listados de artistas italianos contemporáneos, en Internet, recogen la fecha de su muerte en Milán, en 1967, a los 69 años de edad. Se le llama pintor, grabador y escultor. La ausencia de intervenciones arquitectónicas conocidas, salvo el monumento del Escudo, mueve a pensar que Radic como arquitecto y a lo largo de más de cuarenta años no debió pasar de ejecutar oscuras labores constructivas de poco relieve, tal vez sólo de tipo administrativo. Resulta llamativo tanto silencio documental en una de las épocas más fecundas de la arquitectura italiana, cuando los arquitectos modernistas, art decó, fascistas, futuristas y racionalistas -a veces los mismos nombres recorren todos los estilos-, llenaron de calidad muchas páginas de la historiografía europea.

5. Ibídem, pág. 243. Personaje singular, digno de más amplios estudios, Giovanni Bergamini nació el 29 mayo 1895 en Varzi, provincia de Pavía. Murió en la enfermería provincial de San Bernardino de Génova, el 2 de enero de 1961. En el Archivio Storico Provinciale dei Cappuccini di Genova se conserva una rica colección documental y fotográfica que refleja los diversos ámbitos de actividad del padre Bergamini: predicaciones, conferencias, artículos de periódico, cartas sobre su actividad como capellán militar en España y la organización de cementerios de guerra, y la documentación relativa al apostolado en Bélgica. 


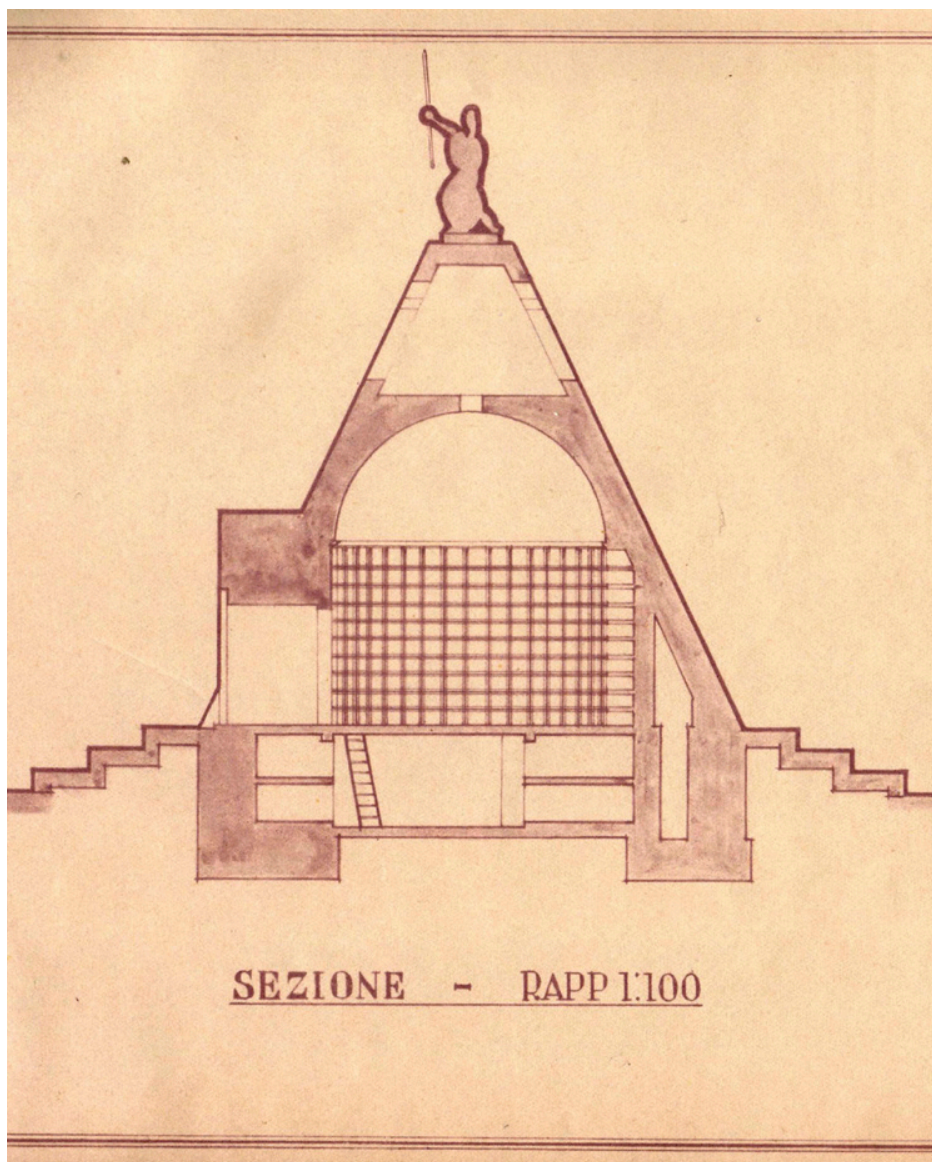

Fig. 4. Dibujo de la sección vertical de la pirámide por Attilio Radic. Foto Archivo Histórico Capuchinos de Génova.
Afortunadamente para la historia del panteón del Escudo, es precioso el contenido del legado del P. Pietro da Varzi existente en Génova, en especial el referente al monumento. Se trata de un conjunto formado por los siguientes elementos ${ }^{6}$ :

“- Cuatro dibujos arquitectónicos, tres de ellos seguramente de mano de Attilio Radic y el cuarto debido al P. Bergamini

- Once fotografías sobre el proceso de construcción de la pirámide y la visita del Conde Galeazzo Ciano

- Siete fotografias de detalle del modelo desmontable de la pirámide, quizás en escayola, y tal vez de mano del P. Pietro da Varzi

- Dos caras de cuartilla escritas en forma de carta por el P. da Varzi, en fecha imprecisa entre 1939 y 1941, con interesantes datos sobre el mausoleo y sus valores simbólicos."

Analizar y comentar estas fuentes gráficas fue el objeto de mi citada publicación en la revista Sautuola.

\section{Valores simbólicos de la pirámide de los Italianos}

En un segundo momento, el citado artículo publicado en el BRACBASJ se dedicó a un minucioso recorrido interpretativo sobre la realidad del sacrario del puerto del Escudo, en su actual estado de conservación, y sobre todo de los documentos históricos antes enumerados.

Comencé por repasar los antecedentes y el contexto histórico-artístico de los elementos del monumento de los Italianos en la montaña burgalesa: así, partí del estudio de la pirámide como tipología arquitectónica muy querida por los visionarios ilustrados y románticos; del rasgo singular de esta pirámide escalonada, y de sus posibles modelos nubios, y al tiempo de su claro sentido metafísico; de la descripción del interior de la pirámide, de su pórtico en forma de "M" a gran escala, y de la puerta con bella cancela art decó; también de la presencia de los fasces como elementos arquitectónicos en el monumento y en la entrada al recinto, y por último del recurso insistente a la epigrafía con valor monumental expresivo, de origen futurista.

\footnotetext{
6. Además de los documentos relacionados a continuación, para la historia personal de los caídos italianos enterrados en El Escudo es muy interesante como demostración de la minuciosidad del P. Bergamini, una Carpeta con el registro del elenco completo de los soldados y oficiales enterrados en el panteón interior, cripta y cementerio exterior, hasta un total de 382. Se señala de cada soldado el nombre y grado, su filiación paterna, unidad de procedencia, y fecha de la muerte, así como la fila y el número del nicho en que se situó su lápida conmemorativa.
} 
También dediqué varias páginas a la reflexión acerca de los valores simbólicos y estéticos del conjunto funerario fascista, resaltando su pertenencia a una arquitectura de la memoria. Formalmente me interesó destacar la importancia de sus rasgos art decó, racionalistas y futuristas, así como la clara inspiración en los grandes sacrari italianos de la primera guerra mundial, debidos en su mayoría al famoso plan Faracovi, que comprendía diversos tipos principales de osarios ${ }^{7}$.

Por último, de este proceso interpretativo resultaron evidentes las afinidades de la pirámide del Escudo con obras expresionistas del arquitecto italo-argentino Mario Palanti, siendo también necesario resaltar los aspectos originales del cementerio cantábrico, enmarcado en esa amplia arquitectura fascista pero, al tiempo, fruto singular de un diseño único en su modesta escala.

Todavía quiero añadir ahora, en este tercer ensayo histórico-artístico dedicado a la Pirámide de los Italianos, que la lectura del artículo que Ignacio González-Varas ${ }^{8}$ dedica a la fascinación por la arquitectura en el paisaje, propia del citado Fernando García-Mercadal, me ha revelado el acusado carácter mediterráneo -traído por Radic hasta el septentrión ibérico-, que significa la forma elegida para el mismo túmulo. Como "representación suprahistórica del pasado como presente", cabe aplicar a su interpretación unas poéticas palabras escritas por Benedetto Gravagnuolo", y definitorias de eso llamado mediterráneo: "Un construir sencillo y armonioso, como simulacro de la ausencia de decoración y de los puros volúmenes euclidianos, como forma simbólica de los cánones auténticos, de la divina proporción, como sombra de la belleza apolínea y como eco de las sirenas transmitido por las olas del mar".

El cementerio del Escudo, paisaje entre la memoria y la ausencia En razón de la batalla, pero también del monumento conmemorativo, El Escudo es en efecto un paisaje histórico, campo de estudio donde se integran las variadas dimensiones del pasado; pero también podría hablarse de un "paisaje ritual". Argumentar esta consideración fundamenta el objetivo del presente estudio.

Dentro del mismo enclave, sobresale en volumen e importancia la Pirámide con su perfil escalonado, más exactamente en sólo dos de sus lados enfrentados (norte-sur), jugando su línea quebrada con el perfil liso del talud de los otros dos paramentos. Tal disposición, que busca la variedad en los puntos de vista del edículo, debe responder directamente a requerimientos propios de la arquitectura art decó, tan cubista en su facetado, en la que se encuadra estilísticamente el edificio funerario. Pero otra posible explicación la proporciona el P.

\footnotetext{
7. Como es lógico, dada la importancia innegable del conjunto de cementerios italianos del periodo de entreguerras, se han llevado a cabo algunos estudios sobre esta llamada "arquitectura de la memoria", entre los que destaca el reciente de Gaetano Palazzolo (PALAZZOLO, Gaetano, "Sub specie aeternitatis. Architettura della memoria in forma di rotonda nel periodo tra le due guerre", Temi di critica e letteratura artística, n. 9, 2014, págs. 62-84), y de cuya lectura se pueden entresacar aspectos muy próximos a lo que encontramos en la Pirámide de los Italianos del Escudo. Señala este autor que el fenómeno de esta arquitectura "in forma de eternitá" deviene como una reacción propia del siglo pasado respecto al positivismo, cuando con muchos rasgos neorrománticos se tendió a proyectar una arquitectura de masas y volúmenes puros y elementales; entre ellos predomina sin duda la rotonda, aunque nunca en exclusiva. Siempre con autonomía plena del ornamento respecto al volumen constructivo, el conjunto de sacrari acabó por conformar en Italia, en los años veinte de la pasada centuria, una especie de ideal patriótico propuesto como meta de peregrinación de carácter propagandístico nacionalista, formándose un circuito de visitas especialmente en torno al curso del Piave, al macizo del monte Grappa y a la campiña de Vittorio Veneto (También hay que citar el volumen dirigido por PIRETTO, Gian Pietro, Memorie di pietra. I monumenti delle dittature, Milano, Rafaello Cortina Editore, 2014, en el que se explica la "fascistización" de la muerte, lograda por medio de los mismos sacrari).

8. GONZÁLEZ-VARAS IBÁÑEZ, Ignacio, "Fernando García-Mercadal...", op. cit., pág. 168.

9. GRAVAGNUOLO, Benedetto, II mito del mediterraneo nell'architettura europea, Napoli, 1994. Citado por González-Varas.
} 


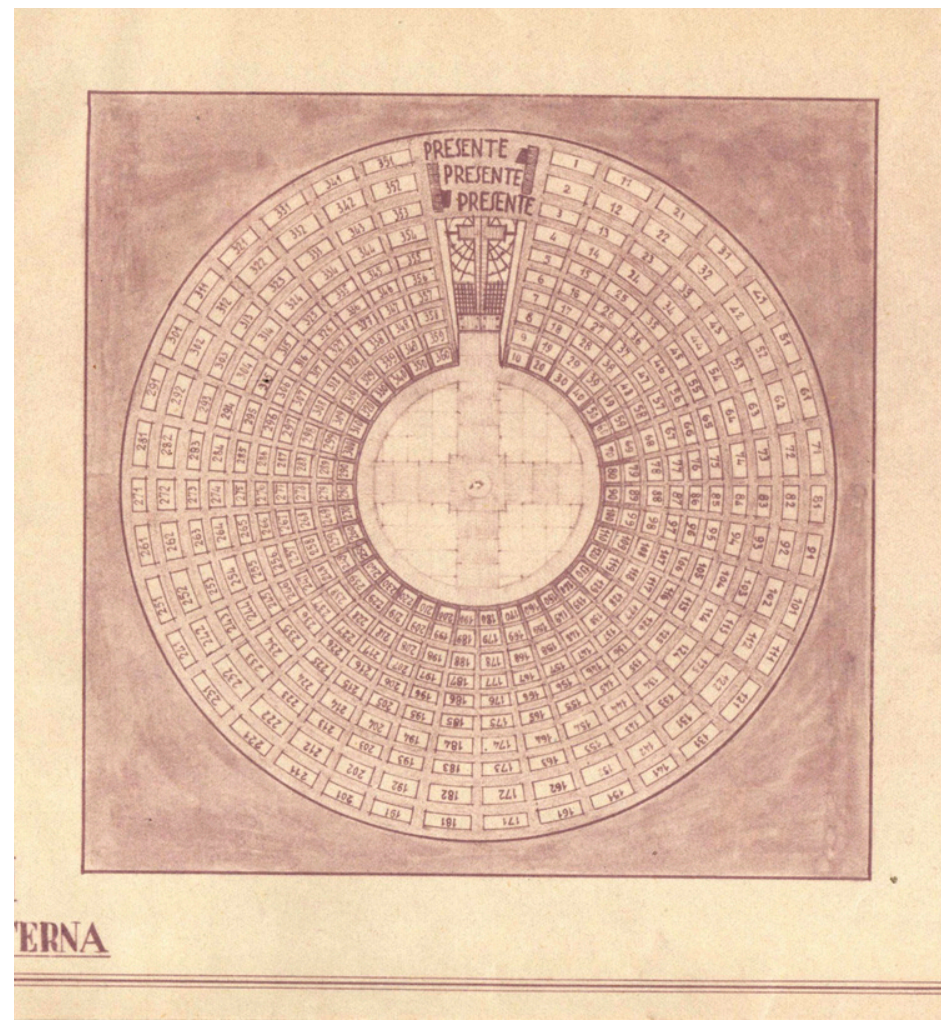

Fig. 5. Dibujo de la vista cónica frontal de la capilla con los lucillos numerados. Foto Archivo Histórico Capuchinos de Génova.

Bergamini en la breve carta que analicé en mi primer artículo citado, cuando dice que los escalones, en ardua subida, simbolizan la dureza de la batalla del Escudo y la conquista de las cotas que hubo que tomar, con gran sacrificio y número de bajas. De esta manera, apreciamos cómo el mausoleo en lo alto de la montaña disputada, adopta a su vez, de modo enfático, la forma geometrizada de la misma montaña, con sus curvas de nivel esquematizadas.

Abundando en este simulacro geográfico, hay que tener en cuenta que una pirámide, sobre todo si está escalonada, se convierte simbólicamente en un camino de subida hacia el cielo, en una montaña ascensional. El mismo año en que se dibuja la pirámide burgalesa ${ }^{10}$, el gran Adalberto Libera diseña en la villa Malaparte de Punta Massulo, en Capri, aquella escalera metafísica que, en forma de pirámide invertida, conduce a la desnuda azotea que se iguala con la línea marítima del horizonte, como una especie de sublimación de la nada. Pero el ideador de este túmulo fascista, así como el P. Varzi como ejecutor práctico, sabían que lo que se representaba en la braña del alto del Escudo era un camino hacia la vida eterna ${ }^{11}$.

El sentido arqueológico de la intervención deriva inmediatamente de la exótica y al tiempo tradicional forma de tumba faraónica, a lo que con el paso de los últimos tiempos se suma el estado ruinoso del cierre del recinto, de su portada principal, y de los restos de fortificaciones militares que se excavaron en el área. Incluso es probable que alguno de los soldados allí enterrados hubiera muerto en el interior de esas mismas trincheras.

El sentido alpestre de la panorámica elegida se infiere de su grandiosidad natural, su altitud, y el dominio geológico de la cordillera cantábrica. Años después se añadió hacia el mediodía la formación del gran lago artificial -como también ocurrió en el mítico Monte Cenis saboyano-, del pantano del Ebro, que añade pintoresquismo a una región aún de clima oceánico. Nieblas frecuentes, lluvia, nieve..., brezos y ginebras, prados alpinos de montańa..., todo contribuye a estos aspectos propios de parajes yermos y antiurbanos.

10. Varios años antes, en 1932, el autor que planeó el cementerio metafísico de Redipuglia, Giovanni Greppi, había manejado a una escala ciertamente gigante el recurso a la escalera de desarrollo ascendente. Poco después, en 1935, el mismo Greppi en el sacrario del Monte Grappa, consigue con semejantes elementos compositivos crear un espacio devocional de claro carácter apocalíptico, en cuanto está inspirado en la versión del Beato Angélico del Juicio Final de San Marcos de Florencia.

11. Un carácter escatológico que también aprecio en el proyecto de Pedro Muguruza para el Valle de los Caídos (vid. MUÑOZ JIMÉNEZ, José Miguel, "El santuario del Valle de los Caídos como Nueva Jerusalén", Academia. Boletín RABASF, Anexo II. Pedro Muguruza Otaño, 2015, págs. 179-196). 


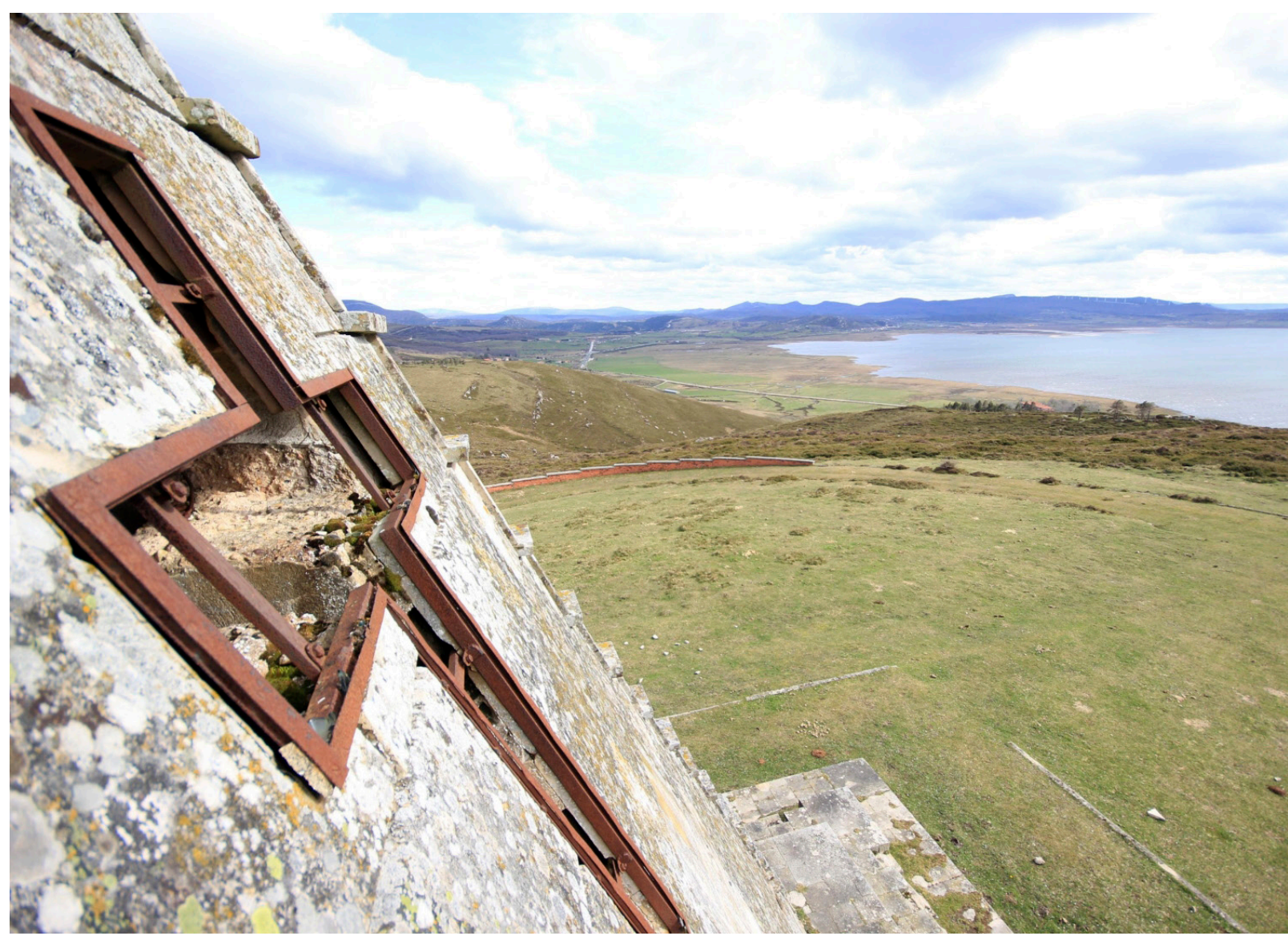

Fig. 6. Detalle claraboya cruciforme lado sur. Foto www.vivecampoo.es (Consultado el 16-04-2017).

El carácter ceremonial, de intencionalidad política pero al tiempo religiosa, también fue bien interpretado por el arquitecto Radic, pues supo conciliar en su cementerio del puerto del Escudo los dos conceptos íntimamente relacionados de la arquitectura de la Memoria y de la arquitectura de la Ausencia. Como ha señalado Richard Etlin, el principio contemporáneo de este planteamiento arranca del gran visionario Etienne-Louis Boullée ${ }^{12}$. En la pirámide cantábrica, ambas categorías se expresan de forma explícita en el recurso frecuente a la invocación epigráfica del “Presente!”.

Pero el creador milanés tenía modelos más próximos en el tiempo y en el espacio: ese magnífico conjunto de grandes cementerios de guerra italianos nacidos como memoriales de un conflicto tan sufrido e ingrato para los italianos - por causa de la decepcionante victoria-, como fue la Gran Guerra. Conviene recordar que el primer paso, lleno de precaución, partía de los ímprobos y desafortunados esfuerzos del concurso nacional para el Monumento al Fante, anunciado en 1920, que debía haberse levantado en el monte San Michele, en el Carso goriziano, lugar de las más cruentas batallas en el frente del Isonzo. Así se crearon las zonas monumentales del monte Grappa, del Pasubio, del monte Cengio y del monte Ortigara.

12. ETLIN, Richard, "El espacio de la ausencia", Una Arquitectura para la Muerte. Actas del I Encuentro Internacional sobre los Cementerios Contemporáneos, Sevilla, 1993, págs. 177-189. 
En todos los casos se aprecia un sentido escatológico que también percibimos en nuestro mausoleo burgalés donde, como en los cementerios alpinos italianos estudiados por el citado Palazzolo, se observa "un nuevo schema, in grado di trasformare glio oggeti-sarcofagi in porte d'ingreso verso estensioni metafisiche al di fuori del tempo, in cui forma e scopo, tecnica ed estetica siano in grado di agire como Petra Genetrix, vortice anulare simbolico scagliato contro l'oscura 'regione dell'Ombra'".

En efecto, el fin último o principal de la cuidada realización de un pequeño recinto urbanizado y arquitectónico en el, desde la batalla del verano de 1937, heroico paraje, debió ser sin duda a los ojos del ejército fascista el crear un "vortice anulare simbolico scagliato contro l'oscura 'regione dell'Ombra". Magnífica definición de una actuación en la naturaleza, propia de un land art antes de tiempo, que explica el carácter ceremonial, tanto en el sentido político como en el sentido religioso, de este hoy maltratado centro devocional.

Por otro lado, como recalqué en el segundo estudio dedicado a este sitio arqueológico, el cementerio italiano de las montañas de Burgos tiene entre otros aspectos de interés el que, junto a unos primeros e incipientes monumentos a los caídos por el bando franquista ${ }^{13}$, constituye los inicios de la utopía arquitectónica de la Autarquía, en aquellos largos veinte años de la postguerra ${ }^{14}$, donde muchos buenos arquitectos españoles -como Palacios, Cabrero, Moya, Fernández-Shaw, Muguruza, etc.-, pretendieron dotar de aspectos cuasi oníricos a los grandes proyectos del llamado nacional-catolicismo. Así, como en el interesante proyecto del citado Moya titulado Sueño arquitectónico para una exaltación nacional ${ }^{15}$-que es versión española anticipadora desde más de un año antes de la misma concepción clasicista de la arquitectura-, la Pirámide de los Italianos ya forma parte de la historia de la "egiptomanía" en España ${ }^{16}$.

Se trata también de un monumento a los caídos, en este caso itálicos, en una guerra extranjera, y muy próximo en su concepción a rasgos tan románticos como "lo sagrado en la orogenia arquitectónica", que Carlos Saguar desentrañó en varios proyectos del arquitecto antes citado Anasagasti ${ }^{17}$, de principios del siglo XX, en patente fusión romántica de arquitectura y naturaleza.

13. Vid. LLORENTE HERNÁNDEZ, Ángel, Arte e ideología en la España de la Postguerra (1936-1951), Madrid, Tesis en la Universidad Complutense de Madrid, 1995.

14. UREÑA PORTERO, Gabriel, Arquitectura y urbanística civil y militar en el periodo de la Autarquía (1936-1945), Madrid, Istmo, 1979.

15. Como se sabe, antes de que se sentaran las bases teóricas para la arquitectura del nuevo régimen franquista, el arquitecto Luis Moya Blanco planteó con ese nombre un conjunto urbano con el que pretendía plasmar sus ideales arquitectónicos más allá de su adscripción política al nuevo régimen, o la utilidad de su proyecto dentro del mismo. Iniciado a finales de 1936 junto con el escultor Manuel Álvarez Laviada; en febrero de 1937 se incorpora el Teniente de Caballería Gonzalo Serrano y Fernández de Villavicencio, Vizconde de Uzqueta. Tituló a este conjunto urbano como "sueño arquitectónico" tanto por la imposibilidad de su materialización como por la carga idealista que contiene. La imposibilidad de materializar el proyecto no fue reñida con su viabilidad constructiva y Luis Moya determinó tanto el emplazamiento (ubicado entre el Hospital Clínico y el antiguo cementerio de San Martín, actual Estadio Vallehermoso, y cuyos cipreses reutiliza) como la configuración constructiva de todos sus elementos, prestando cuidado incluso a sus detalles. El conjunto se organiza a partir de dos ejes sobre los que destacan dos elementos principales: un arco triunfal y una pirámide hueca en torno a los cuales se estructuran varias plazas con edificios militares y administrativos, http:// otraarquitecturaesposible.blogspot.com.es/2012/01/, (Consultado el 30 de octubre de 2014).

16. SAGUAR QUER, Carlos, "Egiptomanía y arquitectura en España (1840-1940)", Goya, n. 259-260, 1997, págs. 386-406, excelente recopilación y análisis del fenómeno a lo largo de cien años. Por cierto que el mismo Luis Moya labró una pequeña capilla funeraria con forma de pirámide truncada, con pórtico delantero y rematada por una cruz, en el jardín del colegio de los Marianistas de Carabanchel. Conviene recordar por otro lado, dadas las afinidades entre estos dibujos de Moya y la ideación de Attilio Radic para el mausoleo del Escudo, que el profesor Antón Capitel ha explicado cómo la arquitectura clásica y moderna realizada sobre todo en Madrid por el arquitecto Luis Moya Blanco, está relacionada con los grandes arquitectos europeos del clasicismo tardío, tales como Lutyens, Perret, Muzio, Böhm y Plecnik, y ha tratado así de ver a este singular arquitecto no tanto dentro de la arquitectura propia de la dictadura franquista, tal y como ha sido tópicamente tratado, sino en relación con la gran cultura clásica tardía del siglo XX europeo.

17. SAGUAR QUER, Carlos, "Teodoro Anasagasti: poemas arquitectónicos", Goya, n. 229, 2000, págs. 49-58. 
Por último en esta valoración sobre el carácter ceremonial del paisaje que rodea a este monumento, pionero respecto a la arquitectura del primer franquismo, entiendo que, formalmente, debe ponerse también en relación con los diseños de enclaves conmemorativos debidos al arquitecto Pedro Muguruza, a quien se le ha definido como el artífice más idóneo para semejantes obras debido a su dominio del dibujo, su fluida colaboración con la escultura y los escultores, su control de la escena urbana e incluso su capacidad para controlar las implicaciones paisajísticas de algunas de sus actuaciones ${ }^{18}$.

De entre los diversos proyectos del vasco, encuentro en El Escudo una directa relación más que con el valle de Cuelgamuros, con el diseño del Camposanto a los Mártires de Paracuellos, del año de 1942, hoy conservado en el archivo de la RABASF. Todo, en ambos casos, está presidido por un mismo orden compositivo extremadamente sencillo.

Al tiempo, en cuanto monumento coetáneo nacido directamente de un suceso bélico común, la Pirámide de los Italianos está íntimamente vinculada con la obra del Águila de la Columna Sagardía, situada al sur en la misma carretera Burgos-Santander, en el término de Cilleruelo de Bezana. Es obra escultórica y arquitectónica de bello estilo y ambiciosa escenografía hoy casi destruida, también art decó, que para 1939 había diseñado el arquitecto Eduardo Olasagasti Irigoyen (1909-1975) ${ }^{19}$, y que construyó José Antonio Olano y López de Letona; y también con el sencillo altar de campaña del páramo de Masa, donde se habilitó un pequeño cementerio provisional, y con algunas otras obras defensivas relacionadas con la misma batalla del Escudo, por lo que encontramos en esa comarca burgalesa un magnífico conjunto de testimonios arquitectónicos de la última guerra civil que sobrepasa en extensión el paraje concreto, dominado por el remolino iconográfico que se intentó conformar a partir del mausoleo italiano en su retórica fascista de Muerte, Victoria y Gloria.

\section{Un sacrario, como la Pirámide de los Italianos, es un mausoleo convertido en santuario} Ahora que los especialistas empiezan a valorar los aspectos simbólicos del paisaje arqueológico de carácter ceremonial, resulta lamentable el olvido que este espacio conmemorativo, tan integrado en el recio ambiente de las brańas de la cordillera cantábrica, sufre de forma creciente por culpa del vandalismo y de la despreocupación de las autoridades. Como se ha visto, El Escudo es santuario fúnebre y religioso, y sobre todo buena arquitectura ideada entre la búsqueda de lo eterno, la ensońación futurista-fascista ${ }^{20}$ y una cierta estética art decó de claros orígenes milaneses. Se trata en efecto de un paisaje histórico, campo de estudio donde se integran las variadas dimensiones del pasado; pero también podría hablarse de un paisaje ritual.

18. Vid. GONZÁLEZ-VARAS IBÁÑEZ, Ignacio, "La plasmación de la memoria: Muguruza y el monumento conmemorativo", Academia. Boletín RABASF, Anexo II. Pedro Muguruza Otaño, 2015, págs. 81-102. Ello en obras oficiales de prestigio que se convirtieron en hitos monumentales allí donde se levantaron, y que incluso se presentaron, en el caso de los homenajes a los caídos, como símbolos del régimen político surgido tras la Guerra Civil.

19. El dibujo frontal que presento del monumento, de mano de Olasagasti, está incluido en el libro GENERAL SAGARDÍA, Del alto Ebro a las fuentes del Llobregat. Treinta y dos meses de guerra de la 62 División, Madrid, Editora Nacional, 1940. Muy reciente, vid. BERNAL LÓPEZSANVICENTE, Amparo, "Arquitecturas efímeras y escenografías de propaganda franquista durante la guerra civil española", Archivo Español de Arte, n. ${ }^{\circ} 362$, 2018, págs. 159-174, quien apenas se ocupa de este magnífico monumento, e ignora la proximidad de la Pirámide de los Italianos. Define bien los servicios de ensalzamiento del Régimen en los años últimos del conflicto.

20. Coincido plenamente con SAGUAR QUER, Carlos, "La cruz soñada: concepción y construcción del Valle de los Caídos", AIEM, 2005, págs. 757-796, cuando en un magnífico estudio reconoce idénticas constantes en el santuario de Cuelgamuros. 


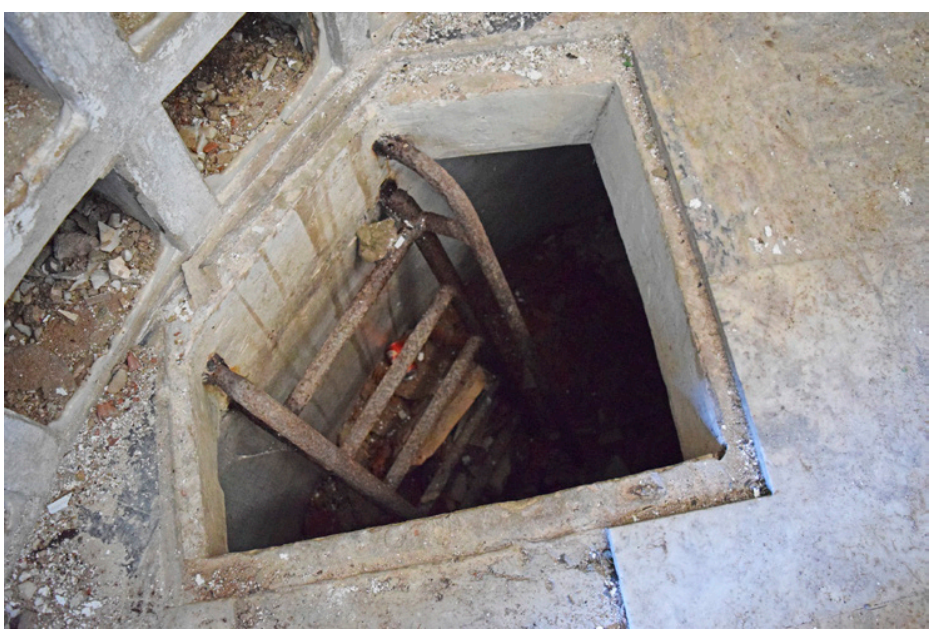

Fig. 7. Detalle de la trampilla de descenso a la cripta. Foto www.vivecampoo.es (Consultado el 16-04-2017).
En concreto, la dimensión simbólica del paisaje se refiere al lado no visible, oculto e inmaterial de la matriz espacial de la cultura. Hablamos del entorno imaginado y pensado, construido figurativamente; de la domesticación simbólica de la naturaleza; del Paisaje más allá de su realidad física, como abstracción de diferentes significados que generan los lugares que lo conforman, es decir, paisajes rituales y étnicos. Se trata de una realidad social históricamente construida, de un sistema de referencia y de una composición del mundo donde las diferentes actividades adquieren sentido.

En palabras de Sánchez Yustos ${ }^{21}$, los paisajes rituales o sagrados son el resultado de aquellas acciones estereotipadas, actos específicos y secuencias de actos, que presentan órdenes socialmente preceptuadas a través de las cuales los grupos definen, legitiman y mantienen la ocupación de un área, enfatizando su visibilidad por medio de su monumentalismo y su ceremonial. Se trata, en mi opinión, de una excelente definición de santuario, aplicable a la mayor parte de los miles de centros devocionales rurales que podemos encontrar en la Europa católica.

Esto del paisaje sagrado y sacralizado es un tema que me ha ocupado durante largos años ${ }^{22}$ : al analizar la faceta paisajística de los santuarios españoles -y partiendo de la hipótesis antes citada de que el cementerio de los Italianos debe ser valorado como un auténtico santuario apocalíptico, con ciertos matices de singularidad-, no sólo debe interesar el paisaje en sus aspectos estéticos, naturalistas, sanitarios y proto-ecológicos, sino que asimismo es fundamental la sacralización del mismo, por medio de la presencia de una ermita. Es la voluntad religiosa del hombre la que procura dicha santificación, que se constata con mucha más fuerza cuando la multiplicación de capillas hace acto de presencia en una misma población -con la consagración del ámbito urbano-, un mismo paraje, o una misma comarca. No es aventurado afirmar que muchas veces la presencia de una o varias ermitas en una elevación próxima a la villa, la transforma en un auténtico Monte Calvario, lo que de inmediato convierte el núcleo en la Nueva Jerusalén, quedando unidos ambos puntos generalmente por una vía sacra más o menos monumental. Estamos así, cuando todo peñón cercano a la población se hace Gólgota y lugar de prácticas piadosas, ante un claro ejemplo de creación por medio de requerimientos religiosos de una geografía imaginaria, que se superpone a la geografía real.

En ocasiones se supera lo hierosalimitano al intentar reconstruir, a escala regional, un país santo, una Nueva Palestina, como se puede ver en comarcas sacralizadas con una gran concentración de templos

21. Vid. SÁNCHEZ YUSTOS, Policarpo, "Las dimensiones del paisaje en arqueología", Munibe. Antropologia-Arqueologia, n. 61, 2010, págs. 139-151).

22. MUÑOZ JIMÉNEZ, José Miguel, "Los santuarios rurales en España: Paisaje y paraje (La ordenación sagrada del territorio)", Actas del Simposium "Religiosidad Popular", vol. II, San Lorenzo de El Escorial, 1997, págs. 307-327, y Arquitectura, urbanismo y paisaje en los santuarios españoles, Madrid, 2010, págs. 427-471. 
(el Montsant, en Tarragona, es un magnífico ejemplo de lo que decimos). Por este camino podríamos llegar hasta la fabulosa región de los países imaginarios. Pero es una realidad, en definitiva, que la presencia de una ermita devota santifica un paisaje, a veces admirable en su carácter escarpado. Nunca se olvide, por cierto, que el interior del túmulo burgalés se concibió en forma y función de capilla, en torno a un altar sacrificial, en el que se celebraron eucaristías en favor de la salvación de los soldados allí depositados.

Otra coincidencia del enclave fascista que me ocupa con muchos de los santuarios rurales hispánicos fue la atracción por lo panorámico, fundamentada en esa estrecha relación entre paisaje y romanticismo, indudablemente achacable en El Escudo a la figura del P. Bergamini, que así actuó como otras muchas mentes cultas que eligieron y promovieron los a veces mal llamados santuarios populares ${ }^{23}$.

Sin embargo, es obvio que en todas las culturas antiguas el culto a los montes santos fue uno de los tópicos habituales. Sea por tradición, o por la simple exaltación de la subida, de la proximidad al Cielo, el cristianismo heredó esta costumbre en centenares de santuarios. Habría que definir qué factor es el más fuerte en la ubicación de esos santuarios de montaña: si la tradición pagana, el afán de la ascensión, y la consiguiente subida penitencial, o el ansia de goce de una panorámica espectacular por parte de los ojos del devoto, sin olvidar el objetivo de situar la imagen a más altura para así aumentar el alcance de su "territorio de gracia". En este sentido sabemos por documentos de la época y por la vista general dibujada del cementerio de los Italianos, que el P. Varzi situó una estatua de la Virgen con el Nińo en un lateral del camposanto, figura que al parecer se conserva hoy en el sacrario italiano de Zaragoza.

Hablando de los factores necesarios para la ideación del centro devocional del Escudo, cabe señalar que, junto a los naturales, muchas veces el factor de localización de un santuario es de tipo humano, histórico en su acepción global. No obstante es fácil que se combinen razones diversas y se acompañen de las referencias geográficas antes mencionadas. Sería el caso de los eremitorios, origen de tantos monasterios y santuarios, que lógicamente han buscado espacios de difícil acceso y marcado carácter natural, proto-ecológicos, a la búsqueda de la más directa comunicación del alma del solitario con la divinidad. El páramo, el yermo, explica su situación, a veces de tipo rupestre, por más extremada, en la recreación de una verdadera geografía imaginaria, como paisaje del descarnamiento, que sueńa con trasladarse al Egipto, la Arabia Felice, la Siria o la Capadocia. Generalmente ello se hará en paisajes de rara belleza.

Por último, la cuestión me hace recordar que en ocasiones el santuario, refugio del hombre en medio del desierto, se presenta a los ojos del que llega como una pequeña fortaleza o ciudad amurallada, con su cerca o tapias que delimitan el recinto sagrado y defienden de los peligros del entorno salvaje. En los casos más característicos, la imagen de la Jerusalén Celestial es algo más que un tópico habitual en occidente. En el reino milenarista de Nueva Espańa, muchos pueblos de indios nos hablan del deseo franciscano por dotar a sus protegidos de un ambiente urbano y social que fuera ensayo, en medio de una naturaleza hostil, del Reino de Dios.

\footnotetext{
23. Soy consciente de que el amor del hombre a las alturas, al dominio de la naturaleza por medio de la subida a las cumbres, es una manifestación tardía de la modernidad, que irrumpió con la llegada del romanticismo. La atracción por lo espectacular, lo pintoresco y lo panorámico, son todos frutos del siglo XVIII y de la aparición de una nueva sensibilidad filosófica. Esto explicará el enriquecimiento de significaciones que en el siglo XIX, con el citado movimiento cultural, cobrará la localización de algunos santuarios más antiguos, que se revalorizan ahora en la línea de la exaltación de la naturaleza, lo cosmogónico y lo sublime (este sería el caso español de Covadonga y de Montserrat). Estos conceptos se suman entonces a lo pintoresco, cuyo nacimiento se produjo en la centuria anterior.
} 


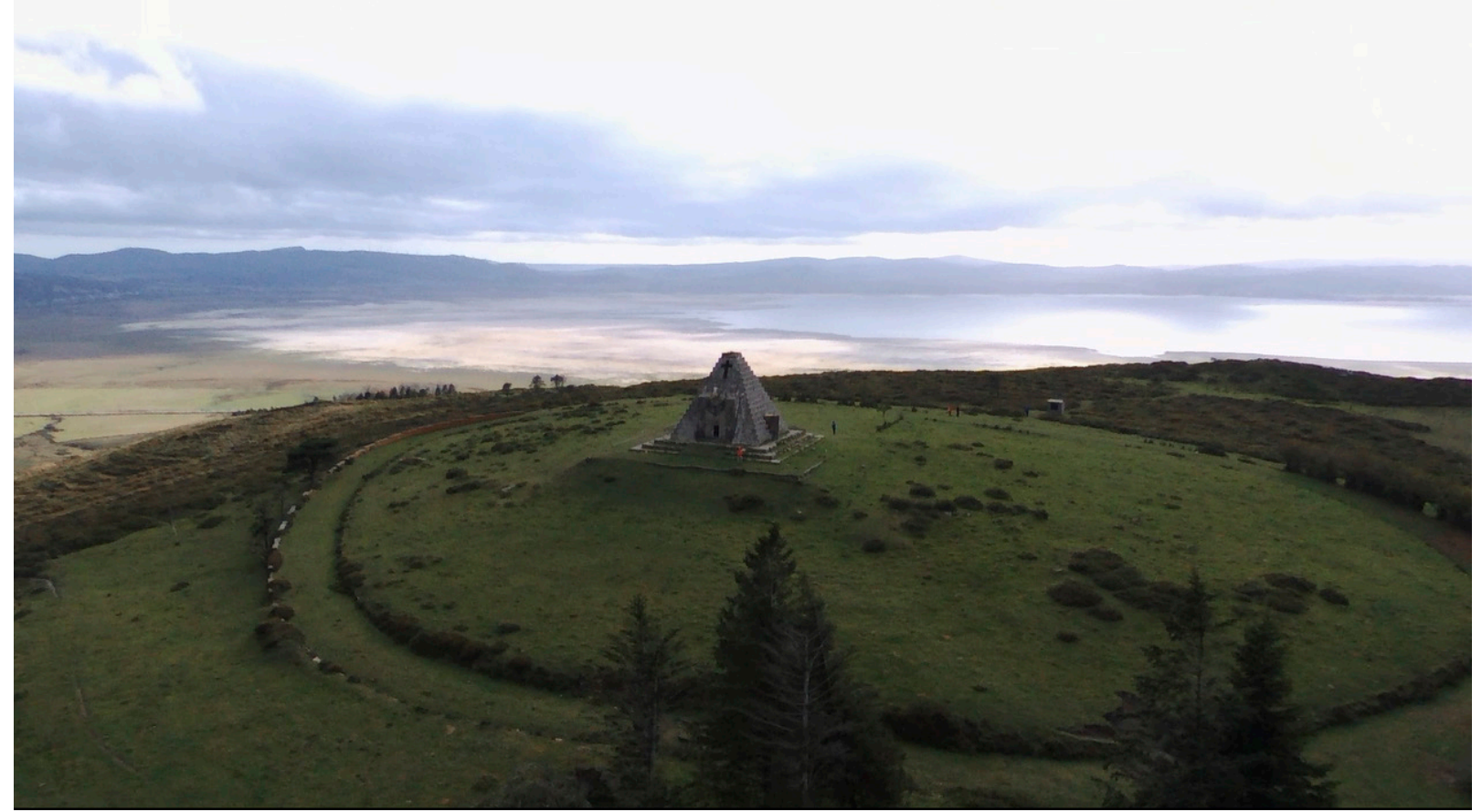

Fig. 8. Panorámica general de un paraje ritual a conservar y restaurar. Foto https://arquitecturasinmemoria.wordpress.com/ (Consultado el 27-01-2015).

En resumen, encontramos innumerables variables en los innumerables santuarios rurales populares de España. Tantas que podría perderse la clave de todo este fenómeno etno-religioso, pero también artístico. Ésta sería, sencillamente, que se trata del culto a Dios, siempre único, pero milagrosamente multiplicado en una casi infinita manifestación cosmogónica ${ }^{24}$. El santuario fúnebre organizado en torno al cementerio de los Italianos, participa en buena medida de ese mismo afán ascensional, patente en su condición innegable de enclave devocional de montaña.

Cabría hacer una objeción final al reconocimiento de nuestro camposanto como santuario religioso, lleno también por su origen y finalidad de innegables aspectos políticos e ideológicos: sería la de la no existencia de devotos que acuden periódicamente al lugar. Pero nótese que con una asiduidad que poco a poco se hizo más laxa, hasta su desmantelamiento en los inicios de los años setenta del siglo pasado, El Escudo recibía la visita de familiares, deudos y correligionarios de los caídos italianos allí enterrados; las fotografías de los actos, con eucaristía incluida, tienen un aspecto próximo al de pequeñas romerías en otros muchos enclaves de la nación, con asistencia también de autoridades españolas en casi todas ellas.

Pero aún se puede añadir otro argumento a favor de que la pequeña necrópolis fue un verdadero santuario, y es el hecho de que contó durante más de treinta años con una especie de guardián o santero,

24. La pirámide del Escudo es deudora también de una larga tradición histórica, que una y otra vez vuelve al modelo egipcio como punto de inspiración para desarrollar un cementerio heroico. Pero al tiempo hay que reconocer que, hacia delante, el tipo de pirámide escalonada siguió siendo válido en la arquitectura postmoderna, como puede verse por ejemplo en los dibujos de Aldo Rossi para el cementerio metafísico de San Cataldo en Módena, de 1971-1978, y unos años antes en la capilla piramidal del varias veces citado Monte Cenis saboyano. 
que lo cuidaba, y que atendía a los visitantes explicándoles detalles del mausoleo. Se trata siempre de una curiosa historia ${ }^{25}$.

\section{Conclusiones}

Para el raro viajero que, desde el litoral septentrional, se topa en lo alto del collado con la Pirámide de los Italianos, su insólita estampa es algo así como una despedida de las brumas atlánticas, lo que le puede acrecer las ganas de surcar, al modo unamuniano, los mares mesetarios desde allí visibles.

En este ensayo se ha visto que, paisajísticamente, confluyen en la ubicación del santuario variados aspectos naturales y artificiales, históricos y religiosos, así como también, para el alma cultivada, se produce una sensación de frustración melancólica al contemplar el vandalismo que el monumento sufre y sufrirá, ante la falta de madurez cultural de una vieja nación que, asombrosamente, se resiste a morir a causa de su propia entropía.

Mas al entendido en los valores de la arquitectura histórica, le puede servir de consuelo la actitud del personaje con cuyas palabras empezaba este artículo, García-Mercadal, quien en su moderada heterodoxia -que no era eclecticismo ni desorientación-, supo siempre que la modernidad sólo es posible desde la verdadera puesta en valor de la tradición, y que es desde la modernidad cuando la verdadera esencia de la tradición adquiere un valor especial ${ }^{26}$. Esta sería la mejor lección que Attilio Radic, aquel modesto artífice milanés, nos ha dejado con su mediterránea obra de la Pirámide de los Italianos.

\section{Bibliografía}

BERNAL LÓPEZ-SANVICENTE, Amparo, "Arquitecturas efímeras y escenografías de propaganda franquista durante la guerra civil española”, Archivo Español de Arte, n. ${ }^{\circ} 362$, 2018, págs. 159-174.

ETLIN, Richard, "El espacio de la ausencia”, Una Arquitectura para la Muerte. Actas del IEncuentro Internacional sobre los Cementerios Contemporáneos, Sevilla, 1993, págs. 177-189.

GENERAL SAGARDÍA, Del alto Ebro a las fuentes del Llobregat. Treinta y dos meses de guerra de la 62 División, Madrid, Editora Nacional, 1940.

GONZÁLEZ-VARAS IBÁÑEZ, Ignacio, "Fernando García-Mercadal. Arquitectura y paisaje mediterráneos”, CASTAÑO PEREA, Enrique (ed.), Academia. Boletín RABASF, Anexo III. Fernando García Mercadal, 2017, págs. 161-184.

GONZÁLEZ-VARAS IBÁÑEZ, Ignacio, "La plasmación de la memoria: Muguruza y el monumento conmemorativo", Academia. Boletín RABASF, Anexo II. Pedro Muguruza Otaño, 2015, págs. 81-102.

\footnotetext{
25. "El gran Elías Rubio Marcos, cronista de la provincia, entrevistó a Félix López Hernando que fue el vigilante del cementerio desde 1946 hasta 1975. En los últimos noventa era el único vecino del pueblo de El Escudo aunque había nacido en Venta Nueva. "El primer día que los italianos tiraron hacia aquí desde La Maza nos mataron un cerdo y nos destrozaron la casa: "Franco paga", nos dijeron". Y la paga fue que, después de acabada la guerra encontró un puesto de trabajo como conserje del panteón de El Escudo. Le nombró el consulado de Italia en Santander con un sueldo de 500 pesetas de la época y seguridad social. Félix mantenía limpio el panteón y se lo enseñaba a las visitas que venían desde Italia. Para una correcta identificación la embajada le había entregado un libro con los nombres de los soldados, el regimiento y el batallón al que pertenecían. Como conserje asistió a las misas de difuntos que anualmente se celebraban. Cada dos años asistía el embajador de Italia en España" (Tomado de Internet, Blog de Lobato de Mena, 12 de marzo 2017).

26. RODRíGUEZ GARCÍA, Ana, "Popular, regional...", op. cit., pág. 217.
} 
GRAVAGNUOLO, Benedetto, Il mito del mediterraneo nell'architettura europea, Napoli, 1994.

MUÑOZ JIMÉNEZ, José Miguel, "Los santuarios rurales en España: Paisaje y paraje (La ordenación sagrada del territorio)", Actas del Simposium "Religiosidad Popular", vol. II, San Lorenzo de El Escorial, 1997, págs. 307-327.

MUÑOZ, JIMÉNEZ, José Miguel, Arquitectura, urbanismo y paisaje en los santuarios españoles, Madrid, 2010. MUÑOZ JIMÉNEZ, José Miguel, "El santuario del Valle de los Caídos como Nueva Jerusalén”, Academia. Boletin RABASF, Anexo II. Pedro Muguruza Otaño, 2015, págs. 179-196.

MUÑOZ JIMÉNEZ, José Miguel, "La pirámide de los Italianos en el Puerto del Escudo (1938-1939): documentación de su proceso constructivo", Revista de Arqueología Sautuola, Instituto Sautuola, XXI, Santander, 2016, págs. 239-252.

MUÑOZ JIMÉNEZ, José Miguel, "Una arquitectura de la memoria: tipo, estilo y simbología de la Pirámide de los Italianos en el puerto del Escudo (1938-1939)", Butlletí de la Reial Academia Catalana de Belles Arts de Sant Jordi, XXXI, 2017, págs. 127-142.

PALAZZOLO, Gaetano, "Sub specie aeternitatis. Architettura della memoria in forma di rotonda nel periodo tra le due guerre", Temi di critica e letteratura artística, n. ${ }^{\circ}$ 9, 2014, págs. 62-84.

PIRETTO, Gian Pietro (dir.), Memorie di pietra. I monumenti delle dittature, Milano, Rafaello Cortina Editore, 2014.

RODRÍGUEZ GARCÍA, Ana, "Popular, regional y mediterráneo. Fernando García Mercadal y su tiempo", CASTAÑO PEREA, Enrique (ed.), Academia. Boletín RABASF, Anexo III. Fernando García Mercadal, 2017, págs. 185-220.

SAGUAR QUER, Carlos, “Egiptomanía y arquitectura en España (1840-1940)”, Goya, n. o 259-260, 1997, págs. 386-406.

SAGUAR QUER, Carlos, “Teodoro Anasagasti: poemas arquitectónicos”, Goya, n. o 229, 2000, págs. 49-58.

SAGUAR QUER, Carlos, “La cruz sońada: concepción y construcción del Valle de los Caídos”, AIEM, 2005, págs. 757-796.

SÁNCHEZ YUSTOS, Policarpo, "Las dimensiones del paisaje en arqueología”, Munibe. AntropologiaArqueologia, n. ${ }^{\circ}$ 61, 2010, págs. 139-151.

URENA PORTERO, Gabriel, Arquitectura y urbanistica civil y militar en el periodo de la Autarquía (19361945), Madrid, Istmo, 1979. 